\title{
JUVENTUDE JUVENTUDES: DOS CONTORNOS SOBRE O CONCEITO ÀS IMPLICAÇÕES DE UM PROGRAMA SOCIOEDUCATIVO
}

Edinólia Lima Portela ${ }^{1}$

\section{RESUMO}

Estudo qualitativo que se utiliza de dados quantitativos, inicialmente realiza reflexão sobre o fenômeno juventude, a partir da visão de estudiosos preocupados com a problemática. Ressalta a visão sociológica do conceito advogada por Bourdieu (1983), Margulis e Urresti, (1996), Sposito (2000, 2002), passando pela defesa de Peralva (1997) e Dayrell (2007). Confirma que, juventude é um conceito socialmente construído, portanto, influenciado por condições materiais, históricas e políticas. Situa a juventude pesquisada como parte daquela que pertence aos estratos sociais mais baixos, evidenciando assim a conjuntura e dados que se articulam com o referencial discutido, o qual fornece elementos para localizá-la como uma entre as várias juventudes existentes no contexto estudado, com o fito de identificar a condição juvenil dos egressos do ProJovem em estudo. Objetiva ainda apurar as implicações do programa no que se refere à continuação dos estudos e ao acesso às oportunidades de trabalho, finalidades estabelecidas pelo ProJovem, para os jovens que o frequentam. Em relação à metodologia deste trabalho, participaram da pesquisa 74 egressos, e foram realizados grupos focais e aplicação de questionário como instrumental de pesquisa. $O$ resultado do estudo conclui que os jovens pesquisados não dispõem de moratória social, mas carregam em si a condição de juventude construída em torno deles e que, a despeito de inúmeras variáveis contextuais, o ProJovem contribuiu para que os egressos prosseguissem os estudos,

\footnotetext{
${ }^{1}$ Doutora em Educação. Professora Associada do Curso de Pedagogia e do Programa de Pós Graduação da Universidade Federal do Maranhão - UFMA. Integrante do grupo de Pesquisa: Escola Currículo e Formação Docente PPG em Educação/ UFMA. Membro do Fórum de Educação de Jovens e Adultos do Maranhão. ORCID: https://orcid.org/00000001-9678-322X. E-mail: edinolia.portela@ufma.br.
} 
embora estejam inseridos em trabalho considerados de menor valor social.

Palavras-chave: Condição de Juventude. Construto Social. Prosseguimento da Escolarização.

\section{YOUTH YOUTHS: FROM THE CONTOURS ABOUT THE CONCEPT TO THE IMPLICATIONS OF A SOCIO-EDUCATIONAL PROGRAM}

\section{ABSTRACT}

Qualitative study that uses quantitative data, reflects on the phenomenon of youth, from the perspective of scholars concerned with the issue. It highlights the sociological view of the concept advocated by Bourdieu (1983), Margulis; Urresti, (1996), Sposito (2000/2002), passing through the defense of Peralva (1997) and Dayrell (2007). It confirms that youth is a socially constructed concept, therefore, influenced by material, historical and political conditions. It places the researched youth as the part that belongs to the lowest social strata, thus evidencing the situation and data that articulate with the discussed framework, which provides elements to locate it as one among the various youths existing in the studied context, with the aim of identifying the youth condition of the ProJovem graduates under study. It also aims to investigate the implications of the program with regard to the continuation of studies and access to work opportunities, purposes established by ProJovem, for the young people who attend it. Regarding the methodology of this work, 74 graduates participated in the research, and focus groups and a questionnaire were applied as research tools. The result of the study concludes that the young people surveyed do not have a social moratorium, but carry within themselves the condition of youth built around them and that, despite numerous contextual variables, PROJOVEM contributed to the graduates continuing their studies, even though they are inserted in work considered of lesser social value. 
Keywords: Status of Youth. Social construct. Continuation of Schooling.

\section{JUVENTUD JUVENTUDES: DE LOS CONTORNOS DEL CONCEPTO A LAS IMPLICACIONES DE UN PROGRAMA SOCIOEDUCATIVO}

\section{RESUMEN}

Estudio cualitativo que utiliza datos cuantitativos, inicialmente reflexiona sobre el fenómeno de la juventud, desde la perspectiva de los estudiosos preocupados com el tema. Enfatiza la visión sociológica del concepto defendida por Bourdieu (1983), Margulis; Urresti, (1996), Sposito (2000/2002), pasando por la defensa de Peralva (1997) y Dayrell (2007). Confirma que la juventud es un concepto construido socialmente, por lo tanto, influenciado por las condiciones materiales, históricas y políticas. Sitúa a los jóvenes investigados como parte de aquellos que pertenecen a los estratos sociales más bajos, evidenciando así la situación y los datos que se articulan con el tema discutido, lo que brinda elementos para ubicarlos como um grupo a más entre los diversos jóvenes existentes en el contexto estudiado, con el fin de identificar la condición juvenil de los egresados del Projovem en estudio. También tiene como objetivo investigar las implicaciones del programa en cuanto a la continuación de estudios y el acceso a oportunidades laborales, fines establecidos por el ProJovem, para los jóvenes que de él participan. En cuanto a la metodología de este trabajo, 74 egresados participaron de la investigación, y se aplicaron grupos focales y un cuestionario como herramientas de investigación. El resultado del estudio concluye que los jóvenes estudiados no tienen una moratoria social, sino que llevan consigo la condición de juventud construida en torno a ellos y que, a pesar de numerosas variables contextuales, el ProJovem contribuyó para que los egresados continuaran sus estudios, a pesar de estar inseridos en trabajos considerados de menor valor social. 
Palabras clave: Situación de la juventud. Construcción social. Búsqueda de la escolarización.

\section{INICIANDO A DISCUSSÃO}

O fenômeno juventude tem suscitado inúmeros estudos nas últimas décadas. Ainda assim, esse campo se constitui fértil em discussões. Estudar tal fenômeno se apresenta como um desafio, a começar por sua definição, tendo em vista que nela habita, sobretudo, uma problemática sociológica. Desta forma, para entendê-lo, precisamos nos apropriar de critérios que o considerem de um ponto de vista tanto histórico quanto cultural.

Torna-se necessário ressaltar, inicialmente, que a imprecisão conceitual do fenômeno decorre, dentre outros fatores, porque essa categoria se estende por contextos e situações com poucos elementos comuns entre si (SPOSITO, 2000). A mencionada visão sinaliza que juventude não é uma "etapa social de vida" homogênea. É objetivamente uma categoria não permanente, transitória e fugaz, em razão de ser composta por indivíduos que concentram em si uma moratória temporal - "um tempo de ser jovem". Assim, na medida em que os anos passam a moratória se esvai e, pela impermanência inexorável do tempo, a juventude vivenciada atualmente cede invariavelmente o seu lugar à próxima juventude.

Daí entendermos um ponto fundamental, isto é, o fato de que, mesmo se tomarmos um recorte temporal para a análise desse fenômeno, os critérios de ordem histórica e cultural precisam ser considerados, assim como outros elementos contextuais inferidos por esses critérios, tais como a situação econômica e social. Parte daí então o entendimento de Schmitt (1996), quando expressa a natureza simbólica potente e ao mesmo tempo ambígua e frágil do conceito juventude.

Deste modo, podemos notar que juventude não é uma categoria apenas natural e biológica, mas uma construção social que varia de acordo com a cultura na qual se encontra inserida, e que sofre variações, mesmo se considerada no âmbito de uma mesma 
cultura. Além disso, também a visão psicológica ${ }^{2}$ sobre esse fenômeno precisa ser levada em conta ao tratarmos dessa problemática.

Esse trabalho foi inspirado em uma pesquisa que compreendeu os anos de 2008 a 2012, desenvolvida em rede por três universidades federais sobre percursos escolares de jovens egressos de um programa de inclusão de jovens, tendo como foco o ProJovem Urbano $^{3}$. Estudo retomado pelo esforço de um egresso do ProJovem Urbano do ano de $2008^{4}$.

No percurso desse artigo buscamos referenciais teóricos que nos possibilitassem entender as discussões sobre as diversas juventudes da atualidade, para assim compreender onde se situa a juventude para a qual se destina o programa de inclusão.

\section{DA COMPREENSÃo CONCEITUAL À LOCALIZAÇÃO DA JUVENTUDE ESTUDADA}

Na tentativa de iniciar uma discussão da autonomia da categoria juventude em relação a outras categorias sociais, como religião, etnia e gênero, Catani e Gilioli (2008) apontam vários fatores a serem considerados nesse debate, afirmando que esses podem se interrelacionar entre si para melhor explicar o significado de juventude, quais sejam: faixa etária; maturidade/imaturidade pelas variáveis biológicas e psicológicas; critérios socioeconômicos; estado de espírito e estilo de vida.

Seguindo outra perspectiva, os estudos de Fraga e Iulianelli (2003) dividem a compreensão de juventude em duas partes, a saber: do ponto de vista dos indivíduos, que seria uma condição transitória; e do ponto de vista conceitual, o que implicaria em uma produção

\footnotetext{
${ }^{2}$ A abordagem psicológica sobre a juventude data de 1904 com a obra Adolescence, de Stanley Hall, bem antes da tradição sociológica.

${ }^{3}$ Programa de Inclusão de Jovens, implantado no ano de 2005, em atendimento aos jovens na faixa etária de 18 a 29 anos, sem trabalho formal, que iniciaram o Ensino Fundamental, mas, não haviam concluído. Esse estudo refere-se a edição especial do ProJovem Urbano realizado entre os anos de 2017 /2018, pela prefeitura de São Luís, utilizando os últimos recursos econômicos do MEC, destinado a esse programa.

${ }^{4}$ In memoriam
} 
sócio-histórica, na medida em que suas funções específicas e o seu entendimento dependem da época e da sociedade em que estão inseridas. Contudo, independentemente da época e do contexto sócio-histórico, notamos na literatura, e em quase todas as sociedades, um ponto comum e um paradoxo: juventude associada à reprodução e à mudança social.

No que tange à compreensão sociológica, as análises apresentadas por Dayrell (2007), igualmente como as demonstradas por Peralva (1997), partem do princípio de que juventude é uma representação e uma condição social. No entanto, ao analisar o conceito, Dayrell acrescenta ao entendimento a ideia de condição juvenil, na perspectiva de alcançar as duas dimensões que o termo compõe. Condição juvenil seria não somente determinada pelo "[...] momento do ciclo da vida, no contexto de uma dimensão históricogeracional", mas, prioritariamente "[...] o modo como tal condição é vivida a partir dos diversos recortes referentes às diferenças sociais classe, gênero, etnia, etc." (DAYRELL, 2007, p. 02).

Sendo assim, condição juvenil seria de caráter interno e individual, quando referida à forma como o sujeito se comporta perante a vida e perante a sociedade; e de caráter externo, quando referida às situações objetivas de organização social em que se desenvolve essa condição.

Outra questão que amplia o debate é a relação entre a juventude da atualidade e as juventudes das gerações anteriores: "O contexto social, político, econômico, cultural e tecnológico no qual está inserida a juventude atual apresenta características e dimensões distintas daquelas vividas pelas gerações passadas" (DUARTE et al., 2009).

Além disso, a existência de mais de uma juventude em um determinado momento histórico conjuntural nos leva a pensar nos aspectos da não homogeneização, ou seja, juventudes que estão no mesmo espaço físico e temporal, mas que em geral são distintas entre si, mormente porque não usufruem de modo igualitário dos bens socialmente produzidos, fator que, quando considerado, acrescenta e fertiliza as análises.

Ao circunscrever a juventude da atualidade em uma visão única, Dubet (1996, p. 26) destaca que 
A cultura dos jovens é aquela de uma modernidade de massa; ela apela à autonomia, aos valores da expressão e da individualidade. Ela se diferencia claramente dos modelos adultos, instituindo uma moratória juvenil na qual cada um tem o direito de fazer experiências e de viver sua vida

Aliado a essa compreensão, o referido autor inclui o prolongamento da formação escolar e a autonomia como elementos definidores da juventude da atualidade. Embora se compreenda que os estudos de Dubet tomem como referência a realidade francesa, tais aspectos apresentam similaridades com outras conjunturas sociais. No que se refere ao prolongamento da vida escolar, não podemos deixar despercebido o descompasso existente entre as ideias do autor e a realidade de alguns países em desenvolvimento, em particular a do Brasil, especificamente a realidade dos jovens sujeitos da pesquisa que realizamos.

Ao desenvolver uma revisão teórica sobre esse fenômeno, Sposito (2002) se sustenta em autores como Salem (1986), Dubet (1996), Attias-Donfut (1996) e Peralva (1997), e chega à conclusão de que juventude é uma categoria sociológica. Não descarta, portanto, a visão que considera essa categoria como "etapa de vida", na qual os sujeitos carregam em si especificidades que são influenciadas pelos modos culturais e de sociabilidades.

Além do mais, a autora alia em seus conceitos a perspectiva que entende o fenômeno juventude em razão dos acontecimentos existenciais pelos quais passam os sujeitos nessa fase da vida. No entanto, por não ser esta uma categoria homogênea, os sujeitos que estão no tempo de "ser jovem" não possuem uma única forma de viver, porque além das suas individualidades, os seus processos existenciais são marcados pelo contexto socioeconômico-cultural em que vivem, revelando-se assim as inúmeras diferenças e as desigualdades.

Como juventude carrega em si um tipo de representação simultaneamente ao de condição social, pensamos que decorre também daí a complexidade para precisar o seu conceito (PERALVA, 1997. 
É necessário destacar que o paradigma que compreende a juventude como uma categoria sociológica procede de estudos europeus que datam do período pós-guerra de 1945, quando se observou a necessidade de expansão do processo de escolarização para essa juventude. Esses estudos se constituem como marco para o entendimento do conceito desse fenômeno na modernidade (GALLAND, 2008). Desta forma, a concepção de juventude na Europa foi adotada a partir das especificidades contextuais de cada país, em particular em função das instituições.

Apesar desse fator, os países europeus concordam que juventude é uma fase em que os sujeitos experimentam novidades, sendo essa, portanto, uma etapa de experimentação. Por seu turno, até que possam se afirmar como adultos, as circunstâncias juvenis vão requerer o cuidado e a proteção das instituições como a família e o Estado (DUARTE et al., 2009). Ao contrário do que defende a escola de Chicago, a aludida proposta refere-se à proteção, e não a controle.

Dentre as mencionadas visões, uma em particular dá fluidez ao debate nos últimos anos e que tem se mostrado com ênfase nas pautas das políticas governamentais para esse segmento, principalmente nos países que concentram juventude em estado de pobreza: a compreensão que circunscreve juventude como um problema social que necessita ser resolvido.

Tais estudos são decorrentes da Escola de Chicago, como já referimos, os quais datam da primeira metade do século XX. Essa linha teórica defende que, por se revelar como um problema social, a juventude precisa ser controlada por organismos institucionais como o Estado ou por setores organizados da sociedade civil.

Ao contrário dessa ideia, mas, levando-a em consideração, pois esta subjaz às políticas para juventude da atualidade, as organizações internacionais ONU, Unesco, OIT e as agências multilaterais como BM e BIRD, reconhecendo as lutas políticas e sociais empreitadas pela juventude em favor dos processos democráticos e conjugados por um contingente de forças conjunturais, começaram, proporcionalmente a partir de 1990, a desenvolver e a introduzir na conjuntura atual a visão que defende o jovem como sujeito de direito, definido por sua singularidade, sua especificidade e sua necessidade. 
Nesse novo contexto ideológico, a "juventude" passou a ser entendida como "ator estratégico do desenvolvimento e protagonista da sua própria vida e do social" - protagonismo juvenil - o que, ao oposto da escola de Chicago, gera uma opinião de supervalorização da juventude. Com esse novo entendimento, o segmento social teve a possibilidade de posicionar-se e fixar-se no espaço público como demanda cidadã legítima, passando assim a ser incluído na pauta das agendas das políticas sociais dos países que se preocupam com essa problemática.

Dentre os organismos mencionados anteriormente, a Unesco, ao mostrar preocupação com a juventude, que faz parte dos estratos que necessitam de políticas públicas, a exemplo dos jovens que pesquisamos, defende que essa é uma fase singular da vida, momento em que os jovens têm direitos, mas também muitos deveres. Sustenta em seus estudos que a juventude é um segmento populacional estratégico no desenvolvimento dos países. Considera jovens pessoas na faixa etária de 15 a $29^{5}$ anos e define juventude como:

[...] um período do ciclo da vida em que as pessoas passam da infância à condição de adultos e, durante o qual, se produzem importantes mudanças biológicas, psicológicas, sociais e culturais, que variam segundo as sociedades, as culturas, as etnias, as classes sociais e gênero (UNESCO, 2004, p. 23).

A mencionada definição associa-se àquelas apontadas por Catani e Gilioli (2008), combinando-as entre si. Desse modo, além de compreender juventude como um período de transição, a Unesco enfoca o jovem no "vir a ser", realça sua preparação para o futuro visando à sua condução ao mundo adulto, e não valoriza, portanto, o jovem como o sujeito do tempo presente. No entanto, em seus trabalhos de ações públicas, convoca o jovem a participar como sujeito atuante dessas ações, desde o processo de suas formulações até as avaliações. Observamos ainda que as justificativas para as ações políticas de tal organização permeiam a revitalização da

${ }^{5}$ Ampliado de 24 para 29 anos, a partir de 2004 (UNESCO, 2004). 
compreensão de juventude defendida pela escola de Chicago, bem como a defesa expressa pela Escola de Birmingham.

Por outro lado, ao considerar as variadas formas existentes de "ser jovem" na sociedade atual, Margulis e Urresti (1996, p. 18) justificam que "[...] a multiplicidade de situações sociais em que esta etapa de vida se desenvolve, apresentam os marcos sociais historicamente desenvolvidos que condicionam as distintas maneiras de ser jovem" (tradução nossa). Ao contrário do conceito de juventude defendido pela Unesco, esses autores apontam uma juventude mais concreta, determinam o seu espaço dando-lhe certa precisão. Reforçam o entendimento de que juventude é também um construto social.

Como consequência, ampliamos nossa compreensão para a existência de mais de uma juventude na atualidade que, na sociedade contemporânea, em especial nos centros urbanos, coexistem conjuntos heterogêneos de grupos juvenis, "[...] com diferentes parcelas de oportunidades, dificuldades, facilidades e poder [...]" (ESTEVES; ABRAMOVAY, 2007, p. 23). De acordo com esse ponto de vista, reforçamos a ideia de que o entendimento de juventude decorre da forma como a sociedade conjuga vários fatores a partir do modo como ela concebe o jovem, aliando-se a tal entendimento o momento histórico, as diferenças de etnia, de classe e de grupo.

A existência da imprecisão do conceito do fenômeno também é reforçada pelos estudos de Bourdieu (1983), quando o sociólogo expressa que tal fenômeno não é bem determinado, pois é um dado manipulado pelos mais velhos em detrimento dos jovens para exercerem poder sobre os últimos. Essa manipulação, segundo o autor, consiste no fato de se associar a idade biológica a uma idade social em que os sujeitos manifestariam determinados comportamentos, aspirações, valores e outros aspectos que se caracterizariam como específicos dessa faixa etária. Segundo o autor,

[...] a idade é um dado biológico socialmente manipulado e manipulável; e o fato de falar dos jovens como se fossem uma unidade social, um grupo constituído, dotado de interesses comuns, e relacionar estes interesses a uma idade definida biologicamente já constitui uma manipulação 
evidente. Seria preciso pelo menos analisar as diferenças entre as juventudes, ou, para encurtar, entre as duas juventudes [...] (BOURDIEU, 1983, p. 113).

A partir da citação, percebemos que o autor faz referência aos extremos da categoria juventude: o jovem burguês, que tem acesso aos estudos e a uma vida sem grandes responsabilidades; e o jovem proletário, que precisa começar a trabalhar muito cedo para suprir suas necessidades e as da família, sem, muitas vezes conseguir usufruir da adolescência.

Além da situação explicitada, juventude é também uma condição social que carrega em si uma visão simbólica "de irresponsabilidade e inexperiência" (BOURDIEU, 1983). Constata-se que, juventude como todos os fenômenos socialmente construídos, apresenta uma dimensão simbólica. Contudo, para além do significado simbólico existem outras interpretações sobre juventude.

Pais (2002), alinhado com o pensamento de Bourdieu (1983), faz uma revisão embasada na sociologia de juventude e agrupa esse conceito em duas perspectivas: a primeira traduz juventude como grupo etário composto por pessoas que somam aspectos uniformes e constantes e têm como característica estar vivendo uma fase da vida comum a todos. Nesse entendimento, juventude é um grupo social definido pela idade. Essa perspectiva se aproxima da compreensão defendida pela UNESCO.

A segunda reconhece a existência das múltiplas culturas juvenis, formadas a partir de interesses e inserções sociais, decorrentes de capital cultural, oportunidades ou de situações socioeconômicas. É importante ressaltar que notamos na segunda perspectiva um avanço sobre o primeiro conceito, pois aquela não considera juventude somente como um grupo etário. Nesta perspectiva, juventude se revela como um grupo heterogêneo, identificada por fatores que ultrapassam os limites de idade (PAIS, 2002).

Observamos que apesar desta segunda perspectiva indicar inúmeras possibilidades sobre a categoria, embora de forma distinta e sugerindo diferentes formas de abordagem, essas concepções não se anulam entre si. Desta forma, juventude pode ser considerada um 
grupo etário, quando comparada a outras gerações, e heterogêneo, quando vista como um conjunto social carregado de atributos sociais que precisamente diferenciam os jovens uns dos outros.

$\mathrm{Na}$ perspectiva de apreender o fenômeno juventude na atualidade, Ribeiro (2004) localiza o advento da Revolução Francesa no século XVIII como um momento decisivo para a valorização da juventude e afirma que a emergência das novas concepções e formas de compreensão disseminadas nos últimos tempos resulta da vitória do modo de produção capitalista sobre o absolutismo monárquico, pois, a partir de então, ocorreram mudanças radicais nas formas vigentes de organização social, econômica e política.

$O$ referido autor argumenta ainda que, na sociedade anterior à Revolução Francesa, cultivavam-se padrões estéticos associados à velhice recorrendo a símbolos que representassem distinção social pela nobreza. $O$ antigo regime deu lugar ao ideário do novo com a Revolução Francesa, que se apresentou defendendo a bandeira da liberdade, da democracia e da vida, elegendo a juventude como segmento de transformação para se galgar a felicidade. $O$ alinhamento comumente estabelecido entre juventude e revolução embasa os argumentos do autor, pois afirma que "fazer revolução tenha sido durante boa parte do século $\mathrm{XX}$, uma das grandes vocações dos jovens" (RIBEIRO, 2004, p. 45).

Assim, desde a revolução francesa foi se desenvolvendo a ideia de que juventude está vinculada à liberdade, à força, ao prazer e à beleza. Consequentemente, os pequenos arrebatamentos de irresponsabilidades e as inconsequências seriam vistos pela sociedade como atitudes inerentes à sua condição - uma espécie de ensaio e erro característico da "moratória social"6. Simultâneo a esse processo, a partir da metade do século $\mathrm{XX}$, a divulgação dessas ideias passa a determinar o ideário social, pois estaria plenamente associada à primeira interpretação pós-revolução, aquela que vincula a juventude à noção de não acomodação, de revolução, do questionamento etc. Essa corrente está aliada aos estudos da escola

\footnotetext{
${ }^{6}$ As transformações ocorridas no início do século XX concorreram para que o jovem fosse segregado em escolas, deixando assim de ser socializado juntamente com outras gerações, o que contribuiu para que juventude fosse estruturada como categoria específica(GALLAND, 2008).
} 
de Chicago e vem abrindo espaço para as discussões no campo do conceito de juventude até os dias atuais.

Apesar de, na atualidade, a ideia de liberdade pessoal estar cada vez mais marcada por valores que se associam à juventude ${ }^{7}, 0$ Brasil não vivenciou sempre esse cenário. No início do século passado a maior importância recaía sobre as pessoas com idade produtiva e reprodutiva, e a juventude não tinha função nem destino (KEHL, 2004). No entanto, apesar de as condições de existência dos últimos tempos apresentarem inúmeras adversidades, nos últimos anos, os jovens, aqui entendidos como categoria homogênea, vêm ocupando um lugar de centralidade no mercado. Percebemos que mesmo a juventude desprovida materialmente, como a juventude por nós pesquisada, tem uma veia consumista. Com recente prestígio, o jovem passou a ser cidadão, uma vez que virou consumidor em potencial, tendo em vista que as pesquisas de marketing $\mathrm{O}$ produziram e o definiram como uma nova fatia de mercado $(\mathrm{KEHL}$, 2004).

O jovem tornou-se, por conseguinte, referência de consumo estético ${ }^{8}$ para toda sociedade, e essa função recaiu até mesmo sobre aqueles pertencentes às camadas sociais mais baixas, cabendo preferencialmente a esses o papel de consumidores. No caso dos jovens que fizeram parte da nossa pesquisa, precisam também enfrentar algumas condições que retardam suas autonomias, condições essas que se referem à escolarização - ao exigir a elevação progressiva do tempo de formação escolar - e ao trabalho - devido à escassez de emprego, além da grande competitividade no acesso aos postos no mercado.

Esses fatores, somados a outros referentes às condições psicológicas e de identidade inerentes à condição juvenil contribuem para que permaneçam mais tempo morando com os pais. Como consequência, esse mesmo jovem se torna dependente do seu núcleo familiar, com o agravante de que aqueles cuja família é mais desprovida materialmente ficam sujeitos à vulnerabilidade.

\footnotetext{
${ }^{7}$ Ideia disseminada a partir do movimento de contracultura em 1968, que também passou a ditar moda e estilos de vida para jovens do mundo inteiro.

${ }^{8} \mathrm{~A}$ influência da cultura juvenil sobre o mercado, a indústria e a moda, uma das vertentes dos estudos culturais desse fenômeno.
} 
Afirmamos que, como no contexto de Bourdieu, atualmente a juventude continua carregada de valor simbólico, mas os elementos que determinam esse processo são fortalecidos mais acentuadamente pelo peso dos artefatos e dos recursos da sociedade de consumo do que pela imputação dos mais velhos sobre a juventude, podendo-se afirmar que, com o passar do tempo, o consumo substituiu os mais velhos. Apesar disso, a cisão entre os mundos juvenis desiguais continua, principalmente nos países pobres.

A despeito do consumo referido anteriormente, observamos que esse fenômeno decorre também da convocação para a liberdade, com o advento da Revolução Francesa, pois, longe dos freios morais e religiosos e desligados dos discursos tradicionais, os jovens acabaram por se constituir um estrato de consumidores extremamente poderoso. Como consequência, a sociedade contemporânea atribui à juventude uma referência paradigmática do que é desejável e legítimo, por meio da evocação de artefatos e costumes relacionados ao corpo, à indumentária e ao comportamento (KEHL, 2004), reedificando dessa forma um ideal estético ao agregar à juventude a comercialização de mercadorias.

É sabido que, desde o último século, juventude passou a ser associada a reprodução e mudança social, portanto, dita moda, costumes e formas de viver e conviver. Todavia, no contexto da sociedade atual, com profundas desigualdades sociais, econômicas e de recursos naturais entre países e regiões, e mesmo no âmbito da mesma nação, a juventude não pode ser percebida somente pelo ângulo referencial do consumo, ou seja, juventude não é somente um grupo homogêneo, e entendê-la somente por esse ângulo significaria reduzi-la, empobrecer o seu significado, desmaterializando-a.

Apoiados nessa compreensão e entendendo o paradigma ${ }^{9}$ no qual se concentram as políticas para juventude dos documentos da Unesco, observamos que a noção de juventude pautada somente pela idade tornou-se obsoleta.

De tal modo, o movimento teórico postula uma nova concepção, que compreende a juventude como uma fase da vida

\footnotetext{
${ }^{9}$ Considera o jovem como sujeito de direito e protagonista do desenvolvimento social.
} 
humana em que o jovem desfrutaria de um tempo livre, sem muitas responsabilidades, com concessões sociais de direito ao estudo, em que deve viver novidades, se aprimorar. Portanto, é uma fase de preparação para entrar na vida adulta, isto é, juventude como "moratória social10" passa a ocupar a centralidade dos estudos.

Todavia, se entendermos juventude desse modo, a maioria das pessoas da classe menos favorecida como os jovens beneficiários dos programas de inclusão, que estão na faixa etária considerada fase de juventude, não poderão ser consideradas jovens, uma vez que não dispõem de tempo socialmente livre, ou, se possuem esse tempo, pouco é utilizado para estudos e aprimoramentos. Contrariamente, muitos desses sujeitos precisam trabalhar desde a tenra idade e responsabilizar-se por questões adultas, o que, por consequência, gera saída prematura da escola e torna impossível usufruir dessa fase da vida. Outras vezes, o tempo livre se dá por falta de oportunidades de trabalho ou outras ocupações típicas da idade, como frequência à escola, ao esporte e ao lazer, o que contribui para enveredarem no mundo da contravenção. Novamente, voltamos à questão social, que determina as diversas juventudes.

Ao mergulhar nessa discussão observamos que o elemento "desigualdade social" é um condicionante do conceito estudado, já que mesmo quando os jovens das classes menos favorecidas dispõem de um tempo livre, em geral, é em decorrência de falta de oportunidades. Alinhados com essa compreensão, os autores enfatizam que "Esta circunstância não conduz à moratória social: cria uma condição não desejada, um tempo livre que se constitui através da frustração e da pobreza" (MARGULIS; URRESTI, 1996, p. 13, tradução nossa).

Esses elementos que tratam das diversas concepções acerca de juventude nos possibilitam refletir melhor sobre a juventude pesquisada.

\section{A JUVENTUDE PESQUISADA}

10 Termo desenvolvido por Erikson (1976) no final da década de 50 e atualizado por Margulis e Urresti (1996) décadas depois. 
Se considerarmos a juventude que estudamos pela faixa etária e a compararmos a outras gerações, podemos compreendê-la como parte de uma só juventude ludovicense. Contudo, se levarmos em conta suas especificidades, tais como: o local onde residem, as dificuldades de locomoção, o difícil equilíbrio que fazem para estudar e trabalhar, estas motivadas por suas situações econômicas e culturais, notamos que é mais uma entre as demais juventudes, visto que, os jovens pesquisados residem nos bairros da periferia ${ }^{11}$ de São Luís, onde se concentram os maiores índices de pobreza e vulnerabilidade social. Além disso, são jovens que no contexto de 2017 ainda não tinham concluído o ensino fundamental e não estavam formalmente trabalhando, apesar de desenvolverem as mais variadas tarefas para economicamente manterem a si e contribuírem para o sustento dos familiares.

Coerentemente com o que expressa Bourdieu (1983), os jovens que pesquisamos em São Luís-MA precisam de fato entrar precocemente no mundo do trabalho e acabam por abandonar a escola. São impelidos a agirem assim por força da dificuldade econômica, ou seja, para se manterem ou ajudarem suas famílias, por isso se lançam no mundo do trabalho. Entretanto, para terem melhores opções de emprego precisam da escolaridade que foram obrigados a deixar em segundo plano, e veem no programa de inclusão de jovem a possibilidade tanto de continuar os estudos como de entrarem no mercado de trabalho.

No ano de 2019, localizamos essa mesma juventude por meio de uma amostra de 74 jovens, na qual $73,6 \%$ continuaram com os estudos, a tabela a seguir nos mostra a distribuição dos jovens no nível e nas modalidades de ensino.

Tabela I - Distribuição dos concluintes - egressos. São Luís-MA, 2019.

\begin{tabular}{|c|c|c|}
\hline \multicolumn{3}{|c|}{ Egressos } \\
\hline Estágio da escolarização & Quant. & $\%$ \\
\hline Cursando o Ensino Médio & 14 & 26,4 \\
\hline
\end{tabular}

${ }^{11}$ Coroadinho, Vila Conceição, Ilhinha, para citar apenas alguns. 


\begin{tabular}{|c|c|c|}
\hline Cursando o Ensino Médio/EJA & 39 & 73,6 \\
\hline Total & 53 & 100,0 \\
\hline
\end{tabular}

Fonte: Elaborada pela autora a partir dos dados coletados.

Apesar do mencionado avanço, a complementação da formação escolar básica se constitui, para esses jovens, como um equilíbrio difícil. Esse fato ocorre devido às condições desfavoráveis que eles enfrentam para manter a identidade de alunos. Por terem a centralidade de suas vidas na sobrevivência, esses jovens acabaram precisando arcar com diversos ônus objetivos e subjetivos e, em muitos casos, muito altos. Isto evidencia, que jovens pouco escolarizados e pobres, para permanecer na escola fazem grandes sacrifícios. As falas a seguir traduzem esta afirmativa:

Continuei com os estudos sim, curso a EJA/ Ensino Médio, mas olhe que luta, estudar e trabalhar no pesado é muito difícil, a gente fica cansado demais e precisa muita vontade para continuar, cansativo demais (Sujeito, da pesquisa).

Terminei o PROJOVEM, estou no Ensino Médio, depois vou pra faculdade, mas, é barra ser pobre estudar e trabalhar, às vezes tenho vontade de desistir, porque além de cansativo, tenho dificuldades para entender o conteúdo. (Sujeito da pesquisa).

Além dos dados referentes à escolarização, a pesquisa nos revelou que do quantitativo de 74 jovens, no final do ano de 2019, 41 estavam $^{12}$ formalmente trabalhando. Desses 41,35 eram do sexo masculino e estavam no ramo da construção civil. Os dados coletados se traduziram para nós como surpresa tendo em vista que, nos últimos quatro anos, a contar de 2019, em São Luís, esse setor tem apresentado um decréscimo elevado em relação aos anos anteriores. Dados do Observatório Social de São Luís, o qual está vinculado ao Ministério do Trabalho, revelam o percentual de jovens, na faixa etária

${ }^{12} \mathrm{O}$ uso do tempo verbal no passado, justifica-se porque a pesquisa foi realizada no final do ano de 2019, e como no ano de 2020 iniciou-se a Pandemia de COVID- 2019, acreditamos que os dados tenham decaído. 
de 16 a 29 anos, engajados em locais formais de trabalho entre os anos de 2017 e 2019, a saber:

Quadro I - Jovens de 16 a 29 anos engajados em postos de trabalho em São Luís

\begin{tabular}{|c|c|c|}
\hline Ano & Percentual & Valor absoluto \\
\hline $\mathbf{2 0 1 7}$ & $22,57 \%$ & 34.317 \\
\hline $\mathbf{2 0 1 8}$ & $18,06 \%$ & 33.883 \\
\hline $\mathbf{2 0 1 9}$ & $17,87 \%$ & 43.489 \\
\hline
\end{tabular}

Fonte: Observatório Social de São Luís (SÃO LUÍS, 2019).

No ano de 2019, São Luís contava com 555.709 habitantes com idade inferior a 29 anos, um percentual de $63,87 \%$ da população inteira. Apontavam ainda as pesquisas daquele ano que os $22 \%$ dos jovens que estavam em postos formais de trabalho, em outras palavras, com vínculos garantidos, recebiam uma média salarial de $\mathrm{R} \$$ 833,27 (SÃO LUÍS, 2019). Concluímos que, dentre esses $22 \%$ de jovens com vinculação de trabalho garantida, estavam 41 concluintes do programa.

Embora os dados apontassem para a queda do desemprego em São Luís, e do considerado salário revelado pelo Observatório, o quadro ainda se configurava de forma dramática e estava aquém de atingir os níveis desejados, o que, em outras palavras, significava que ainda existiam/ existem muitos jovens na busca imperiosa por ocupação. Podemos afirmar que alguns entrevistados almejavam tal mudança por razões de afirmação de autonomia, mas, em maioria, em especial os jovens que pesquisamos, estavam/ estão nessa busca por necessidade extrema de obtenção de renda.

Importa dizer que a ampliação da abertura de postos de serviços na área da construção civil, entre os anos de 2009 e 2014, contingenciou a queda da taxa de desemprego, nesse período em São Luís. Contudo, esse cenário não se mostrava promissor, embora um número elevado de egressos, estivessem desenvolvendo atividades de trabalho, e as pesquisas ${ }^{13}$ afirmassem que no ranking

\footnotetext{
${ }^{13}$ Folha de São Paulo, 13/03/2018.
} 
de investimentos em obras o estado do Maranhão estivesse em segundo lugar (MARANHÃO, 2019).

Devemos destacar, entretanto, que esses postos de trabalho são ocupados prioritariamente por jovens pertencentes aos estratos sociais mais baixos, considerados há algumas décadas como o grupo social com maior índice de dificuldades para se inserir em atividades econômicas. Ressaltamos ainda que, na atualidade, anos de 2019, os impactos produzidos pelas mudanças da estrutura de produção também se constituem para esses jovens como um grande desafio.

Notamos que, objetivamente, reside aí um paradoxo, uma vez que, dentre os segmentos sociais, esse se constitui como o que melhor domina a flexibilidade de adaptação imposta pelo surgimento de novas oportunidades, não somente no campo do trabalho. Pensamos que essa facilidade ocorra devido à própria vitalidade inerente à essa faixa etária (MARGULIS; URRESTI, 1996).

Esse capital energético ${ }^{14}$ de alguma forma também possibilita aos jovens que eles estejam "em alerta" quanto a fatos recorrentes que perpassam o imaginário social. Isso contribui para que seja revelado em seus discursos o requerimento da escolarização como condição de entrada nas ocupações do mercado de trabalho, afinal, essa condição se constitui como um dos pré-requisitos exigidos pelas novas relações de trabalho, o que se caracterizou em primeira instância, para a juventude pesquisada, como um passaporte de inserção ao mundo da empregabilidade ${ }^{15}$.

O percurso de escolarização e as condições de trabalho desenvolvidas pela juventude pesquisada também nos permitiu a compreensão de que, se definirmos juventude como moratória social, os jovens egressos do programa pesquisado não teriam juventude, o que nos encaminha a constatar a existência de mais de uma juventude em São Luís - MA.

\footnotetext{
${ }^{14}$ Que coloca os jovens dentro da condição juvenil independente dos estratos sociais a que pertencem.

${ }^{15}$ Os jovens de quem foram exigidos os certificados de qualificação para entrar no mercado de trabalho declararam que, primeiramente, tiveram que concluir o Ensino Fundamental.
} 


\section{PARA CONCLUIR}

O mergulho nas discussões sobre juventude nos possibilitou entender que embora o conceito determinado pela idade cronológica esteja ultrapassado e não dê conta de explicar os múltiplos significados desse segmento na contemporaneidade, não sendo um demarcador confiável nas determinações do conceito, continua sendo uma variável presente nas discussões mais atuais. Observamos que, mesmo que existam diferenças marcantes entre as juventudes da atualidade, determinadas pelo grupo social a que os jovens pertencem, alguns autores como Bourdieu (1983), Sposito (2002) Esteves e Abramovay (2007), encontram pontos comuns a todos os grupos juvenis e comungam com o conceito de juventude como uma construção social.

Além do mencionado, Margulis e Urresti (1996) anunciam um ponto comum entre as juventudes, o que denominam de "moratória vital". Seria uma qualidade de "plus de tempo, uma espécie de capital energético", um tempo inerente à condição de ser jovem, e que lhes daria a sensação de que eles teriam um abundante tempo pela frente, intrínseco a sua condição. Com essa definição, os autores encontram uma base concreta de juventude e um elemento comum às juventudes, independentemente da classe social.

Entendemos o posicionamento dos autores, que se referem à moratória vital remetendo-se a uma única juventude, e na contraposição aos adultos. Entretanto, reconhecemos que outros fatores se entremeiam por essa visão, pois se considerarmos a heterogeneidade juvenil, nos depararemos também, por exemplo, com altos índices de mortalidade de pessoas jovens em países em desenvolvimento, os quais se revelam como dados epidêmicos, significando que em países periféricos, ser jovem e pobre não garante uma vida longa. Esse entendimento nos remete novamente à compreensão do conceito de juventude como socialmente construído, que carrega em si um poder simbólico, mas, ao materializar-se em sociedades social e economicamente desiguais como a nossa revela-se em múltiplas juventudes.

Podemos afirmar que a juventude investigada é uma das juventudes existentes em São Luís que possui características 
singulares como: baixo poder econômico e cultural, que enfrenta inúmeras adversidades para sair dessa condição, e que, apesar de estar na faixa etária de outras juventudes e, em tese, ter a mesma vitalidade, não dispõe de moratória social para usufruir da sua condição juvenil. O esforço que faz para garantir o percurso de escolarização, aliado à luta pela sobrevivência e engajar-se em um trabalho formal, confirmam nossas afirmações e nos encaminham ao entendimento de que juventude é um conceito socialmente construído.

Desse modo, "[...] o seu tratamento deve, obrigatoriamente, considerar as determinações materiais, históricas e políticas inerentes a qualquer produção social" (ESTEVES; ABRAMOVAY, 2007, p. 24). Todavia, apesar dos jovens pesquisados serem parte das múltiplas juventudes de São Luís e estarem entre aqueles que não dispõem de moratória social, não deixam de carregar em si a condição de juventude construída em torno deles.

\section{REFERÊNCIAS}

ATTIAS-DONFUT, Claudine. Jeneusse et conjugaison dês temps.

Sociologie et societé, v. 28, n. 1, p. 3-22, 1996.

BOURDIEU, Pierre. A juventude é apenas uma palavra. In:

BOURDIEU, Pierre. Questões de Sociologia. Rio de Janeiro: Marco Zero, 1983.

CATANI, Afranio M.; GILIOLI, Renato de S. P. Cultura juvenis: múltiplos olhares. São Paulo: UESP, 2008.

DAYRREL, Juarez. A escola "faz" as juventudes? Reflexões em torno da socialização juvenil. Edu. Socied., v. 28, n. 100, out. 2007.

Disponível em: http://www.scielo.br/scielo.php?script=sci_arttext\&pid =S0101 73302011000400010 \&lng=pt\&nrm=isso. Acesso em: 26 jan. 2021.

DUARTE, M. R. T.et al. Perfis de jovens e concepções de juventudes. In: DUARTE, M. R. T. (Org.). Palavras de jovens sobre o Projovem: estudos com egressos e a formação de pesquisadores em avaliação 
de programas educacionais. Belo Horizonte: Escritório de Histórias, 2009. p. 33-56.

DUBET, F. Des jeunesses et des sociologies: lescasfrançais.

Sociologie et Sociétés, Paris, v. 28, p. 23-35, 1996.

ESTEVES, L. C. G; ABRAMOVAY, M. Juventude, juventudes: pelos outros e por elas mesmas. In: ABRAMOVAY, M; ANDRADE. E. R.; ESTEVES. L. C. G. (Orgs.). Juventudes: outros olhares sobre a diversidade Brasília, DF: Ministério da educação, Secretaria da educação Continuada, Alfabetização e Diversidade; Unesco, 2007. p. 19-54.

ERIKSON, E. H. Identidade, juventude e crise. Rio de janeiro: Zahar, 1976.

FRAGA, Paulo C.; IULIANELLI, Jorge A. Jovens em tempo real. Rio de janeiro: DP\&A, Lamparina, 2003.

GALLAND, Olivier. Jeunesse (Sociologie de la). In. VAN ZANTEN, Agnès. Dictionnaire de I' éducation. Paris: PUF, 2008. Disponivel em: http://osc.sciences-po.fr/publication/pub_coulangeon.htm. Acesso em: 3 mar. 2011.

KEHL, M. R. A Juventude como sintoma da cultura. In: NOVAES, R.; VANUCHI, P. (Org.). Juventude e sociedade: trabalho, educação, cultura e participação. Rio de janeiro: Fundação Perseu Abramo, 2004. p. $75-88$.

MARANHÃO. Instituto Maranhense de Estudos Socioeconômicos e Cartográficos. Indicadores da conjuntura econômica do Maranhão 2019. São Luis, 2019.

MARGULIS, Mário; URRESTI, Marcelo. La juventudes más que una palabra. In: ARIOVICH, L. et al. La juventude es más que una palabra. Buenos Aires: Biblos, 1996. p. 13-30.

PAIS, José M. Sociologia da vida quotidiana: teorias métodos e estudo de caso. Lisboa: Imprensa de Serviços Sociais, 2002.

PERALVA, Anglina. O jovem como modelo cultural. Rev. Bras. Educ., São Paulo, n. 5/6, p. 13-28, 1997. 
RIBEIRO, Renato. J. Política e juventude: o que fica da energia. In: NOVAES, R.; VNNUCHI, P. (Org.). Juventude e sociedade: trabalho, educação, cultura e participação. Rio de janeiro: Fundação Perseu Abramo, 2004. p. 34-65.

SALEM, Tania. Filhos do Milagre. Ciência Hoje, v. 5, n. 25, 1986. p 30-36.

SÃO LUÍS. Indicadores de São Luís: observatório social de São Luís. 2019. Disponível em: http://www.nossa saoluis.org.br. 2008. Acesso em: 14 novembro. 2019.

SCHMITT, Jean-Claude (Orgs). História dos jovens: época contemporânea. São Paulo: Companhia das Letras, 1996. v. 2 SPOSITO, Marília P. Estado do conhecimento juventude. Brasília, DF: INEP, 2000.

SPOSITO, Marília P. Juventude e escolarização (1980/1998). Brasília, DF: MEC/ INEP, 2002.

UNESCO. Políticas públicas de/para/com as juventudes. Brasília, DF, 2004.

Submetido em: Julho/ 2021.

Aceito em: Agosto/ 2021. 